\title{
Malignant Thymoma Presenting as Sensorineural Deafness
}

\author{
Gary Hunter, Jennifer Ringrose, Andrew Kirk
}

Can. J. Neurol. Sci. 2008; 35: 265-266

Thymoma is well known to have a strong association with autoimmune disorders, most notably myasthenia gravis (MG) which is seen in up to $40 \%$ of cases..$^{1,2}$ There are also a number of other less common autoimmune disorders associated with thymoma, including hyperexcitability syndromes, ${ }^{3}$ myositis, ${ }^{1}$ encephalitis, ${ }^{4}$ autonomic dysfunction, ${ }^{5}$ and lupus. ${ }^{6}$ In 2004 Vernino and Lennon ${ }^{7}$ reported autoimmune sensorineural hearing loss (SNHL) in two patients from their series of 201 patients with thymoma, a previously unreported association. A third case of paraneoplastic SNHL asociated with thymoma was reported by Evoli et al. ${ }^{8}$ We now report a patient presenting with SNHL several years before a diagnosis of malignant thymoma was made. This newly recognized association justifies screening for thymoma as part of the work-up for autoimmune SNHL.

\section{Case Report}

A previously healthy 26-year-old female with no significant medical or family history presented with tinnitus followed by profound sensorineural hearing loss in the right ear over the next two weeks. Audiometry was consistent with sensorineural deafness. The following year she had the same symptoms affecting the left ear leaving her deaf. At age 31 she developed horizontal diplopia with impaired adduction of the left eye. Magnetic resonance imaging scan of the brain and cerebrospinal fluid examination were normal. An edrophonium test did not improve her diplopia. Anti-acetylcholine receptor antibodies were negative, and muscle biopsy of vastus lateralis was unremarkable.

Over the next few months she developed proximal weakness, fatigueable muscles of mastication, and dysphagia. Her edrophonium test was now strongly positive. Computed tomogram scan of the chest confirmed the presence of a large thymic mass, and microscopic analysis revealed prominent nucleoli and high mitotic counts consistent with malignant thymoma. The mass was resected and followed by radiotherapy. Her anti-acetylcholine receptor antibodies were now strongly positive at $7.79 \mathrm{pmol} / \mathrm{L}$. Repetitive nerve stimulation was also positive with $14 \%$ decrement. She was treated with pyridostigmine and prednisone which was tapered gradually, and she remained stable for several years.

At age 38 she presented with shortness of breath and was found to have a large left pleural effusion which was considered parapneumonic in nature. She soon developed bilateral effusions which tended to reaccumulate for the next several years requiring multiple thoracenteses.

Follow-up chest $x$-ray at age 43 revealed a mass involving the left breast and sternal border, which was confirmed on biopsy to be recurrent malignant thymoma. The patient was admitted to hospital with increasing shortness of breath and required intubation and ventilation for respiratory failure. Further testing revealed a strongly positive ANA and anti-DNA antibodies. In the setting of renal insufficiency and pleuritis, these findings were diagnostic of lupus. She was treated with plasmapheresis but showed no improvement in respiratory function and passed away in hospital.

\section{DISCUSSION}

While the association of thymoma and myasthenia is welldescribed, less common entities such as encephalitis, myositis, autonomic neuropathy, and lupus may complicate the diagnosis and clinical course. To add to the list of potential autoimmune disorders associate with thymoma, we now report a third case of sensorineural deafness associated with thymoma, in this case malignant. The large series published by Vernino and Lennon ${ }^{7}$ did not find association between type of autoimmune disease and histologic subtype of thymoma, although the number of cases of less common entities was low, making this association challenging.

Autoimmune sensorineural deafness has been described in association with various other autoimmune diseases, including rheumatoid arthritis, systemic lupus erythematosus, polyarteritis nodosa, Sjogren's syndrome, and ulcerative colitis..$^{9}$ The typical course is acute, with severe hearing loss taking place over daysweeks, and the other ear becoming affected months or years later. The etiologic antibodies are unkown, although anticochlear antibodies have been found in $35 \%$ of a series of 54 patients, ${ }^{10}$ and $32 \%$ of 279 patients in another series had antibodies to an

\footnotetext{
From the Department of Neurology (GH, AK), Department of Medicine (JR), University of Saskatchewan, Saskatoon, Saskatchewan, Canada.

Received July 31, 2007. Final Revisions Submitted November 8, 2007. Reprint requests to: Gary Hunter, 107445 Bayfield Cr., Saskatoon, Saskatchewan, S7V 1J1, Canada.
} 
antigen similar to heat shock protein 70 (hsp70). ${ }^{11}$ The mechanism is also unclear but there is evidence for impaired integrity of the blood-labyrinth barrier. ${ }^{12}$ Treatment consists of immunosuppression with steroids alone or in combination with cyclophosphamide, and plasmapheresis has shown promise as an alternative for progressive cases. ${ }^{13}$

\section{Conclusions}

Thymoma has long been associated with various autoimmune disorders, but the association with SNHL has only recently been described. Patients presenting with a clinical picture of autoimmune SNHL should be screened for thymoma with a minimum of plain chest x-ray and ideally with a CT scan of the chest. This association is likely under-recognized and its recognition may hasten diagnosis and treatment for patients with thymoma.

\section{REFERENCES}

1. Souadjian JV, Enriquez P, Silverstein MN, Pepin JM. The spectrum of diseases associated with thymoma. Coincidence or syndrome? Arch Intern Med. 1974 Aug;134(2):374-9.

2. Goulon M, Estournet B, Tulliez M. Myasthenia gravis and associated diseases. Int J Neurol. 1980;14(1):61-72.

3. Vernino S, Auger RG, Emslie-Smith AM, Harper CM, Lennon VA. Myasthenia, thymoma, presynaptic antibodies, and a continuum of neuromuscular hyperexcitability. Neurology. 1999 Oct 12; 53(6):1233-9.
4. Rickman OB, Parisi JE, Yu Z, Lennon VA, Vernino S. Fulminant autoimmune cortical encephalitis associated with thymoma treated with plasma exchange. Mayo Clin Proc. 2000 Dec;75(12):1321-6.

5. Vernino S, Cheshire WP, Lennon VA. Myasthenia gravis with autoimmune autonomic neuropathy. Auton Neurosci. 2001 May 14:88(3):187-92.

6. Bozzolo E, Bellone M, Quaroni N, Voci C, Sabbadini MG. Thymoma associated with systemic lupus erythematosus and immunologic abnormalities. Lupus. 2000;9(2):151-4.

7. Vernino S, Lennon VA. Autoantibody profiles and neurological correlations of thymoma. Clin Cancer Res. 2004 Nov 1;10(21): 7270-5.

8. Evoli A, Minicuci GM, Vitaliani R. Paraneoplastic diseases associated with thymoma. J Neurol. 2007 Jun;254(6):756-62.

9. Mathews J, Kumar BN. Autoimmune sensorineural hearing loss. Clin Otolaryngol Allied Sci. 2003 Dec;28(6):479-88.

10. Harris JP, Sharp PA. Inner ear autoantibodies in patients with rapidly progressive sensorineural hearing loss. Laryngoscope. 1990 May; 100(5):516-24.

11. Billings PB, Keithley EM, Harris JP. Evidence linking the 68 kilodalton antigen identified in progressive sensorineural hearing loss patient sera with heat shock protein 70. Ann Otol Rhinol Laryngol. 1995 Mar;104(3):181-8.

12. Trune DR, Kempton JB, Hefeneider SH, Bennett RM. Inner ear DNA receptors in MRL/lpr autoimmune mice: potential 30 and $70 \mathrm{kDa}$ link between autoimmune disease and hearing loss. Hear Res. 1997 Mar;105(1-2):57-64.

13. Luetje CM. Theoretical and practical implications for plasmapheresis in autoimmune inner ear disease. Laryngoscope. 1989 Nov;99(11):1137-46. 